\title{
ANALISIS KELAYAKAN USAHA SARI BUAH BELIMBING DI KOTA BLITAR
}

\author{
Jabal Tarik Ibrahim, Ary Bakhtiar \\ Dosen Jurusan Agribisnis, Universitas Muhammadiyah Malang, Indonesia \\ email: jabaltarik2012@gmail.com
}

\begin{abstract}
Star fruit cultivation business has become one of the economic supports for people from Karangsari, Blitar. Number of star fruit production continuing to increase by years in which it becomes the background of people from Karangsari in making innovative products from star fruit star fruit. This study aims to determine the feasibility of star fruit juice business. The research was conducted at "Cemara Sari", Self-Finance Agricultural Training Center and Rural (P4S), in Karangsari, Blitar. The location selection used purposive sampling technique by considering that Blitar is the center of fruit star fruit development in East Java. The allocation time for the study start from August to September, 2014. Star fruit extract business is considered financially feasible. It can be seen from the value of NPV by $R p$ 45.728.311, -; Net $B / C=4.09$; gross $B / C=1.3$; profitability $=7.3$; and IRR by $89.13 \%$.
\end{abstract}

Keywords: star fruit, star fruit extract, business feasibility.

\section{PENDAHULUAN}

Pertanian di Indonesia memiliki berbagai kontribusi pada perekonomian Negara, antara lain: menyerap tenaga kerja pedesaan, meningkatkan pendapatan petani, menyediakan pangan, menyediakan bahan baku industri, sumber devisa, dan dan kontribusi dalam bentuk capital. Namun diakui, untuk membangun pertanian agar lebih progresif masih juga ditemui berbagai kendala, salah satunya adalah investasi. Apriantono (2004) menyatakan bahwa investasi pertanian masih lemah dan seadanya. Lemahnya investasi ini karena banyak investor menganggap bahwa sektor pertanian masih high risk dan low profit dan term of trade produk pertanian rendah. Masalah permodalan sebenarnya sudah diidentifikasi oleh teknis di bidang ini.

Dalam rangka memperbesar akses petani pada perbankan atau sebaliknya mengorong lembaga keuangan masuk ke sektor pertanian, pihak Bank Indonesia telah banyak mengupayakan studi pola pembiayaan berbagai komoditas pertanian. Kantor Perwakilan Bank Indonesia di berbagai daerah memiliki banyak aktivitas yang menunjang kesuksesan hal ini. Kantor Perwakilan Bank Indonesia Kediri adalah salah satu kantor perwakilan Bank Indonesia yang memiliki kepedulian yang tinggi akan hal ini. Aktivitas peningkatan cluster cabai merah, pengembangan lele, dan pola pembiayaan nanas telah dilakukannya akhir-akhir ini. Sambutan para pihak seperti petani, pedagang hasil pertanian, pedagang sarana produksi pertanian, dinas teknis terkait, serta lembaga-lembaga keuangan begitu tinggi dan positif. (Ibrahim, 2012).

Belimbing manis (Averhorrhoa carambola L) menjadi buah eksotis karena ukuran buahnya besar, warna menarik, serat buah halus, berair banyak, dan rasanya manis segar. Belimbing dapat dijumpai di seluruh wilayah Indonesia, namun daerah yang terkenal sebagai penghasil belimbing unggul adalah Blitar, Demak, Depok, Jepara, Jakarta Selatan, Deli Serdang, dan Ogan Komering Ilir (Dirjen Hortikultura, 2004; Rukmana, 2006 Agromedia, 2009).

Belimbing manis memiliki beberapa varietas, antara lain varietas dewi, varietas demak kapur, demak kunir, varietas paris, varietas bangkok, varietas si manis, varietas wulan, varietas wijaya, varietas sembiring, varietas filipina, varietas taiwan, dan varietas karangsari. Buah belimbing dapat diolah menjadi beberapa produk makanan/minuman, antara lain: Sari buah belimbing, sirup belimbing, manisan belimbing, dodol/jenang belimbing, dan permen belimbing. Tujuan penelitian adalah untuk mengidentifikasi aspek kelayakan usaha pada usaha olahan belimbing. 


\section{METODE PENELITIAN}

Penelitian ini dilaksanakan di Pusat Pelatihan Pertanian dan Pedesaan Swadaya (P4S) Cemara Sari Kelurahan Karangsari Kecamatan Sukorejo Kota Blitar Provinsi Jawa Timur. Penentuan lokasi ini menggunakan teknik purposive sampling dengan pertimbangan bahwa Kota Blitar merupakan daerah sentra pengembangan buah Belimbing di Jawa Timur. Waktu penelitian berlangsung pada bulan Agustus hingga September tahun 2013. Analisis data dalam penelitian ini menggunakan kaidah kriteria investasi. Berikut adalah rumus dari kriteria investasi:

\section{Net Present Value (NPV)}

NPV adalah selisih antara benefit (penerimaan) dengan cost (pengeluaran) yang telah dipresent valuekan. Kriteria ini mengatakan bahwa proyek akan dipilih apabila NPV $>0$. Dengan demikian, jika suatu proyek mempunyai NPV $<$ 0 , maka tidak akan dipilih atau tidak layak untuk dijalankan (Pudjosumarto, 2002).

$$
N P V=\sum_{r=0}^{r s} \frac{(B t-C t)}{(t+i)^{\prime}}
$$

Kriteria yang digunakan :

- $\quad N P V>0$, usaha layak untuk dijalankan

- $\quad N P V=0$, usaha tersebut mengembalikan sama besarnya nilai uang yang ditanamkan

- $\quad N P V<0$, usaha tidak layak untuk dijalankan

\section{Net Benefit Cost Ratio (Net B/C Ratio)}

Net $B / C$ Ratio merupakan perbandingan antara benefit bersih dari tahun-tahun yang bersangkutan yang telah dipresent valuekan (pembilang/bersifat + ) dengan biaya bersih dalam tahun dimana $\mathrm{B}_{\mathrm{t}}-\mathrm{C}_{\mathrm{t}}$ (penyebut/bersifat -) yang telah dipresent valuekan, yaitu biaya kotor $>$ benefit kotor. Kriteria ini memberi pedoman bahwa proyek akan dipilih apabila Net B/C ratio $>1$. Dan begitu pula sebaliknya, jika suatu proyek memberi hasil Net B/C Ratio < 1, proyek tidak diterima.

$$
\text { Net } B / C=\frac{\sum_{t=0}^{5} \frac{(B t-C)}{(1+i)^{2}}}{\sum_{t=0}^{5} \frac{(C t-B t)}{(1+n)^{2}}}=\frac{(B t-C t)>0}{(B t-C t)<0}
$$

Kriteria yang digunakan:

- $\quad$ Net $B / C \geq 1$, usaha layak dilakukan

- $\quad$ Net $B / C \leq 1$, usaha tidak layak dilakukan

\section{Internal Rate of Returns (IRR)}

IRR merupakan tingkat bunga yang menggambarkan bahwa antara benefit (penerimaan) yang telah dipresent valuekan dan cost (pengeluaran) yang telah dipresent valuekan sama dengan nol. Dengan demikian, IRR ini menunjukkan kemampuan suatu proyek untuk menghasilkan return, atau tingkat keuntungan yang dapat dicapainya.

$$
I R R=i+\frac{N P V^{+}}{\left(N P V^{+}-N P V\right)} \times\left(r^{+}-r\right)
$$

\section{Kriteria:}

$I R R \geq i$, berarti usaha dapat dilanjutkan

$I R R \leq i$, berarti usaha lebih baik ditolak atau dihentikan.

\section{HASIL DAN PEMBAHASAN \\ Tenaga Kerja}

Tenaga kerja untuk pengolahan belimbing menjadi sirup, sari belimbing selama ini berasal dari dalam keluarga karena masih berupa home industry. Belum ada yang menggunakan tenaga upahan seperti dalam sistem pengupahan pabrik. Jika tenaga kerja itu dihitung maka jumlah kebutuhan tenaga kerjanya dijelaskan dalam tabel 1.

Pada tabel 1 terlihat bahwa jumlah tenaga kerja dan kapasitas produksi per hari masih kecil karena jumlah permintaan yang masih rendah. Jika keadaan tetap seperti ini maka home industry ini akan tumbuh pelan, namun jika promosi dapat meningkatkan permintaan maka pengolah dapat meningkatkan produksi dengan peralatan yang lebih modern dengan kapasitas yang lebih besar.

Tabel 1. Tenaga kerja pembuatan sari dan sirup buah belimbing

\begin{tabular}{llll}
\hline $\begin{array}{c}\text { Aktivitas pengolahan } \\
\text { belimbing }\end{array}$ & TK per hari & $\begin{array}{c}\text { Total kebutuhan TK } \\
\text { (HKSP) }\end{array}$ & Kapasitas produksi/hari \\
\hline Sari & 2 & 576 & $4-9$ kardus $/$ hari \\
& & & $\begin{array}{l}1 \text { kardus }=24 \mathrm{cup} \\
1 \mathrm{cup}=120 \mathrm{ml} \\
4-21 \mathrm{botol} / \mathrm{hari} \\
\text { Sirup }\end{array}$ \\
& 2 & 576 & botol $=650 \mathrm{ml}$ \\
\hline
\end{tabular}

Sumber: data primer 
Tabel 2. Biaya tetap sari belimbing (dalam ribuan)

\begin{tabular}{rlrrrrr}
\hline No & Nama Alat & Jml & $\begin{array}{c}\text { Harga } \\
\text { satuan }\end{array}$ & Total harga & $\begin{array}{c}\text { Lama } \\
\text { pemakaian (th) }\end{array}$ & $\begin{array}{c}\text { Nilai penyusutan } \\
\text { (Rp/bln) }\end{array}$ \\
\hline 1 & Sepeda motor & 1 & 3000 & 3000 & 10 & 300.000 \\
2 & Mesin cup sealer & 4 & 1000 & 4000 & 5 & 600.000 \\
3 & blender & 6 & 200 & 1200 & 2 & 600.000 \\
4 & Kompor gas & 4 & 250 & 1000 & 3 & 333.333 \\
5 & Panci & 4 & 120 & 480 & & 240.000 \\
6 & Ompreng & 6 & 6 & 36 & & 18.000 \\
7 & pisau & 5 & 8 & 40 & & 20.000 \\
8 & Saringan & 8 & 5 & 40 & & 20.000 \\
\hline & & & Jumlah & $\mathbf{9 . 7 9 6 . 0 0 0}$ & $\mathbf{2 . 1 3 1 . 3 3 3}$ \\
\hline
\end{tabular}

Sumber: data primer

\section{Teknologi}

Teknologi yang digunakan untuk produksi olahan belimbing. Proses produksi dilakukan secara sederhana sebagaimana ibu rumah tangga mengembangkan ketrampilan masak-memasak. Peralatan memasak seperti blender, pisau, kompor, pengaduk, saringan, dan nampan adalah peralatan masak dapur rumah tangga pemilik home industry. Pemasangan sealer pada botol sirup belimbing dilakukan secara manual. Pemasangan seal pada gelas plastik sari apel dilakukan dengan sealer manual. Satu mesin sealer yang dimiliki oleh BKM Kridasari bantuan PNPM belum berfungsi optimal karena produksi belum optimal. (P4S Cemara Sari, 2013).

Jika produksi akan ditingkatkan untuk memenuhi permintaan yang lebih banyak maka teknologi peralatan yang dipakai untuk olahan belimbing dapat ditingkatkan ke peralatan yang lebih modern dan kapasitasnya lebih besar.
Misalnya blender atau juicer, peralatan masak, sealer, dan pengkemas kotak.

\section{Kriteria Usaha Olahan Buah Belimbing Sari Belimbing}

Pola usaha olahan belimbing yang ada di Kota Blitar bersifat home industry dengan produksi yang masih kecil dan peralatan manual. Ekspansi pasar olahan belimbing masih dalam jumlah kecil. Jumlah produksi sangat bergantung kepada pesanan, sehingga pada bulan-bulan tertentu memiliki pesanan yang banyak seperti menjelang hari raya Idul Fitri. Pola usaha olahan belimbing dapat ditingkatkan baik kuantitas maupun kualitas jika program promosi bersama atau promosi pemerintah daerah berhasil menaikkan pesanan/permintaan. Pola usaha belimbing dapat ditingkatkan dari home industri menjadi industri kecil. Biaya investasi untuk usaha olahan sari minuman belimbing

Tabel 3. Biaya variabel sari belimbing per satu kali produksi (dalam ribuan)

\begin{tabular}{|c|c|c|c|c|c|}
\hline No & Nama bahan & $\mathrm{Jml}$ & Satuan & Harga satuan & Total harga \\
\hline 1 & Buah belimbing & 312 & $\mathrm{~kg}$ & 3000 & 960.000 \\
\hline 2 & Gula & 72 & $\mathrm{~kg}$ & 11.800 & 849.600 \\
\hline 3 & Asam sitrat & 480 & gr & 22 & 10.560 \\
\hline 4 & Natrium benzoat & 360 & gr & 33 & 11.520 \\
\hline 5 & Air & 144 & liter & 210 & 28.800 \\
\hline 6 & LPG & 8 & tabung & 15000 & 120.000 \\
\hline 7 & Kemasan cup $120 \mathrm{ml}$ & 312 & cup & 240 & 74.400 \\
\hline 8 & Tenaga kerja & 24 & orang & 40.000 & 960.000 \\
\hline \multirow[t]{2}{*}{9} & Biaya listrik & & & & 37.500 \\
\hline & & & & Jumlah & 2.940 .480 \\
\hline
\end{tabular}

Sumber: data primer 
terdiri dari sepada motor, mesin cup sealer, blender, kompor gas, panci, ompreng, pisau, saringan. Masing-masing biaya investasi mempunyai umur ekonomis yang berbeda-beda, sepada motor memiliki umur ekonomis selama 10 tahun dan mesin sealer 5 tahun, sedangkan untuk umur ekonomis alat-alat lain investasi yang kurang dari 3 tahun dilakukan reinvestasi. Biaya perijinan usaha olahan belimbing tidak dihitung dikarenakan usaha tersebut masih dikembangkan dan didukung oleh pemerintah daerah sehingga pengusaha olahan belimbing tidak dikenakan biaya perijinan usaha. Biaya paling besar dalam usaha olahan sari belimbing adalah biaya mesin cup sealer, untuk biaya sepeda motor memiliki nilai lebih kecil dari harga sepeda motor umumnya dikarenakan harga sepeda dipasar dibebankan pada 4 olahan usaha belimbing.

\section{Produksi dan Pendapatan}

Proyeksi produksi dan pendapatan sari belimbing dapat dilihat dalam tabel berikut ini. Produksi per hari sari belimbing sebanyak 13 dus dengan harga Rp 20.000,- per dus.

\section{Proyeksi Arus Kas dan Kelayakan Proyek}

Dari analisis perhitungan menujukkan nilai NPV sebesar Rp 45.728.311,- , yang artinya NPV positif atau NPV $>0$ yang berarti usaha sari belimbing layak untuk dijalankan. Selain NPV, ada beberapa metode untuk mengetahui besarnya keuntungan dalam usaha sari belimbing. Benefit Cost Ratio dalam usaha sari belimbing mempunyai nilai 4.09 yang artinya usaha layak dijalankan.

Analisis perhitungan Gross $\mathrm{B} / \mathrm{C}$ ratio mempunyai nilai 1.3 , sedangkan Profitability Ratio adalah 7.3. analisis Gross $\mathrm{B} / \mathrm{C}$ ratio dan Profitability digunakan untuk mengukur besar kecilnya tingkat keuntungan yang diperoleh dalam hubungannya dengan penjualan maupun investasi. Kriteria Gross B/C Ratio adalah Gross $\mathrm{B} / \mathrm{C}$ Ratio $>1$ dan $\mathrm{PR}>1$ dalam usaha sari belimbing masing-masing analisis memmpunyai nilai lebih dari 1 sehingga usaha sari belimbing layak dijalankan.

\section{Perhitungan Internal Rate Return Sari Be- limbing}

Perhitungan Internal Rate Return usaha sari belimbing dengan masa investasi tahun ke 1 hingga ke 6 , selengkapnya dapat dipaparkan dalam tabel 6 .

Tabel 4. Produksi dan pendapatan kotor penjualan sari belimbing per tahun.

\begin{tabular}{cllr}
\hline No & \multicolumn{1}{c}{ Uraian } & \multicolumn{1}{c}{ Nilai \& Satuan } & Harga \\
\hline 1. & $\begin{array}{l}\text { Produksi Per Hari } \\
\text { Cup } 120 \mathrm{ml} / \text { isi } 24 \text { cup per dus }\end{array}$ & 37 liter/13 dus & 260.000 \\
2. & $\begin{array}{l}\text { Produksi Per Bulan } \\
\text { Cup } 120 \mathrm{ml} / \text { isi } 24 \text { cup per dus }\end{array}$ & 888 liter/312 dus & 6.240 .000 \\
3. $\quad \begin{array}{l}\text { Produksi Per Tahun } \\
\text { Cup } 120 \mathrm{ml} / \text { isi } 24 \text { cup per dus }\end{array}$ & 10.656 liter/3744 dus & 74.400 .000 \\
\hline Sumber: data primer
\end{tabular}

Tabel 5. Perhitungan Net Present Value dan Net Benefit Cost Ratio Sari Belimbing (dalam jutaan)

\begin{tabular}{lllllll}
\hline \multirow{2}{*}{ Uraian } & \multicolumn{7}{c}{ Tahun ke } \\
\cline { 2 - 7 } & 1 & 2 & 3 & 4 & 5 & \multicolumn{1}{c}{6} \\
\hline Penjualan sari belimbing 120 ml & 9600 & 36000 & 50400 & 60000 & 67200 & 74400 \\
\hline Investasi & 4928 & 200 & 388 & 1224 & 656 & 2400 \\
\hline Net Benefit & 16522 & 9819 & 18257 & 23903 & 21769 & 23908 \\
\hline DF 12\% & 0,8928 & 0,7971 & 0,7117 & 0,6355 & 0,5674 & 0,5066 \\
\hline NPV & & & & & & $45,728.31$ \\
\hline Net Benefit Cost Ratio & & & & & 4,09 \\
\hline Sumber: data primer
\end{tabular}


Tabel 6. Perhitungan Internal Rate Return Sari Belimbing

\begin{tabular}{|c|r|c|r|r|r|r|r|r|}
\hline $\begin{array}{c}\text { Ta- } \\
\text { hun }\end{array}$ & Investasi & O\&M & Benefit & Net Benefit & DF 88\% & NPV 88 \% & DF 90 \% & NPV 90\% \\
\hline 1 & 4.928 .000 & 21.194 .500 & 9.600 .000 & $(16.522 .500)$ & 0.531915 & $(8.788 .564)$ & 0,526316 & $(8.696 .053)$ \\
\hline 2 & 200.000 & 25.980 .100 & 36.000 .000 & 9.819 .900 & 0.282933 & 2.778 .378 & 0,277008 & 2.720 .194 \\
\hline 3 & 388.000 & 31.754 .500 & 50.400 .000 & 18.257 .500 & 0.150497 & 2.747 .690 & 0,145794 & 2.661 .831 \\
\hline 4 & 1.224 .000 & 34.872 .100 & 60.000 .000 & 23.903 .900 & 1.080051 & 1.913 .539 & 0,076734 & 1.834 .232 \\
\hline 5 & 656.000 & 44.774 .500 & 67.200 .000 & 21.769 .500 & 0.04256 & 926.956 & 0,040386 & 879.185 \\
\hline 6 & 2.400 .000 & 48.091 .300 & 74.400 .000 & 23.908 .700 & 0.022649 & 541.513 & 0,021256 & 508.200 \\
\hline \multicolumn{2}{|l|}{ Sumber: data primer } & & & & 119.513 & & $(92.410)$ \\
\hline
\end{tabular}

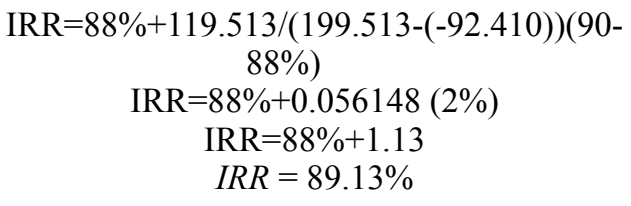

Nilai NPV, Net B/C, gross B/C, dan profitability ratio, dan IRR menunjukkan bahwa usaha sari belimbing layak dijalankan.

\section{KESIMPULAN DAN REKOMENDASI}

Produksi buah belimbing yang tinggi menjadi lebih penting karena pengolahan buah belimbing menjadi produk sari terdapat di wilayah yang sama sehingga menjadi sistem agribisnis yang terintegrasi. Permintaan buah belimbing selalu ada dan dapat dipenuhi oleh petani namun dalam waktu tertentu kadang-kadang terjadi overs supply. Pada saat seperti inilah agroindustry belimbing olahan menjadi sub sektor yang sangat penting bagi perekonomian masyarakat. Usaha sari belimbing dinyatakan layak secara finansial. Hal ini dapat dilihat dari nilai NPV sebesar Rp 45.728.311,-; Net B/C = 4,09; gross $\mathrm{B} / \mathrm{C}=1,3$; profitability $=7,3$; dan IRR sebesar $89,13 \%$.

Berdasarkan survey dan hasil analisis yang telah dilakukan, beberapa hal disarankan untuk tujuan perbaikan kualitas budidaya dan olahan belimbing di masa yang akan datang. Saran-saran yang dimaksud, antara lain:

Olahan belimbing memerlukan teknologi tepat guna yang sesuai dengan situasi, kondisi, dan kemampuan pengrajin/pengolah seperti kapasitas mesin sealer serta proses pengolahan yang higienis.

Pengolah belimbing memerlukan penyuluhan tentang proses pengolahan yang higienis dan bersertifikasi untuk menjamin keamanan produksi sebagai upaya perlindungan atas keamanan konsumen.

\section{DAFTAR PUSTAKA}

Agromedia, Redaksi. 2009. Buku Pintar: Budidaya Tanaman Buah Unggul Indonesia. PT Aromedia Pustaka. Jakarta.

Ibrahim, Jabal Tarik. 2012. Pola Pembiayaan (Lending Model) Budidaya Nanas. Kantor Bank Indonesia Kediri. Kediri.

Kementrian Pertanian RI. 2005. Standar Prosedur Operasional Belimbing Karangsari Kota Blitar. Direktorat Budidaya Tanaman Buah Direktorat Jendral Hortikultura Departemen Pertanian. Jakarta.

P4S Cemara Sari. 2013. Standar Prosedur Operasional Budidaya Belimbing karangsari. Pusat Pelatihan Pertanian dan Pedesaan swadaya cemasari. Blitar.

2013. Pembibitan Belimbing. Pusat Pelatihan Pertanian dan Pedesaan swadaya cemasari. Blitar.

. 2013. Olahan Belimbing. Pusat Pelatihan Pertanian dan Pedesaan swadaya cemasari. Blitar.

Pudjosumarto, Mulyadi. 2005. Evaluasi Proyek, Uraian Singkat Soal-Jawab.Penerbit Liberty. Yogyakarta.

Rukmana, Rahmat. 2006. Belimbing Manis: Budidaya, Pengendalian Mutu, dan Pascapanen. Penerbit Aneka Ilmu. Semarang. 